\title{
Psicologia e ruralidades: caminhos para um fazer psicológico transformador
}

\author{
Psicología y ruralidades: caminos para un hacer \\ psicológico transformador
}

\section{Psychology and Ruralities: paths for a transforming psychological practice}

\author{
Eliana Maria Lopes \\ Universidade Paranaense (UNIPAR), Brasil \\ Clarice Regina Catelan Ferreira \\ Universidade Paranaense (UNIPAR), Brasil \\ Douglas Renan Friedrich \\ Universidade Paranaense (UNIPAR), Brasil
}

Autor referente: ventonorosto@gmail.com

Historia Editorial

Recibido: 10/11/2016

Aceptado: 20/02/2018

\section{RESUMO}

O presente artigo procura construir uma série de reflexões pertinentes sobre o atuar do psicólogo no meio rural, um profissional que na maioria das vezes possui uma formação acadêmica e uma visão urbana de mundo. Para tanto, foi realizado um levantamento bibliográfico com o intuito de apresentar dados sobre a forma como a Psicologia atua junto às populações rurais, destacando-se dentro das políticas públicas brasileiras o trabalho do CRAS (Centro de Referência de Assistência Social) como a principal via através da qual a Psicologia chega ao meio rural em nosso país. Foram igualmente levantadas reflexões sobre os saberes

necessários para que a Psicologia possa apresentar um fazer crítico e pertinente quando inserida na realidade rural. Munido dos pressupostos de uma ciência psicológica eminentemente urbana, o profissional da Psicologia corre o risco de valer-se de uma mera transposição teórica: utilizar no meio rural e em suas comunidades a lógica urbana. Sem a devida reflexão, construída a partir das bases históricas de nossa sociedade, a Psicologia pode acabar sendo uma simples repetidora de preconceitos e culpabilizações, mantendo o estado de naturalização das mazelas sociais. A partir da visão de homem referenciada pela Psicologia Histórico-Cultural, 
necessidade de um comprometimento ético e a utilização de uma epistemologia adequada à realidade rural, capaz de enxergar os problemas da vida real dessa população, e também capaz de gestar coletivamente os caminhos da transformação social.

\section{Palavras-chave: Ruralidades; Psicologia; Psicologia Histórico-Cultural}

\section{RESUMEN}

En este artículo se busca construir una serie de reflexiones pertinentes sobre la labor del psicólogo en el campo, un profesional que a menudo tiene una formación académica y una visión de mundo urbano. Para tanto, se realizó una revisión de literatura con el fin de presentar datos sobre cómo la psicología trabaja con la población rural, con destaque para la política pública brasileña del CRAS (Centro de Referencia de Asistencia Social) siendo esa la principal vía a través de la cual la psicología llega a las zonas rurales de Brasil. También se plantearon reflexiones acerca de los conocimientos necesarios para que la psicología pueda presentar una acción crítica y relevante cuando se inserta en la realidad rural. Armado con las suposiciones de una ciencia psicológica eminentemente urbana, el profesional psicólogo corre el riesgo de valerse de una mera transposición teórica: utilizar en las zonas rurales y sus comunidades la lógica urbana. Sin la debida reflexión, construida a partir de las bases históricas de nuestra sociedad, la psicología puede llegar a ser una simple repetidora de prejuicios y culpabilizaciones, manteniendo el estado de naturalización de los problemas sociales. Desde la visión de hombre amparada por la Psicología Histórico-Cultural, se destaca la necesidad del compromiso ético y del uso de una epistemología adecuada a la realidad rural, capaz de ver los problemas de la vida real de esta población, y también capaz de gestar colectivamente caminos para la transformación social.

Palabras clave: Ruralidades; Psicología; Psicología Histórico-Cultural

\section{ABSTRACT}

This article intends to build a series of relevant discussions on the psychologist's role in the rural context. This professional possesses, most of the time, an academic background based on an urban worldview. For that, a literature review was conducted in order to present data on how psychology works with rural populations. In Brazil, the work of CRAS (Social Assistance Reference Center) features among the public policies as the main channel through which psychology arrives in the Brazilian countryside. Reflections were also raised on the necessary knowledge psychology needs, so it can present a critical and relevant practice when inserted in the rural reality. Armed with the assumptions of an eminently urban psychological science, this professional might undertake a mere theoretical transposition. Without proper pondering and being built from our society's historical foundation, psychology may end up being a mere prejudice and blame repeater, thus, maintaining the naturalization state of the social problems. This work illustrates the worldview of the Culturalhistorical Psychology, making clear the necessity of an ethical commitment and the usage of a proper epistemology to the rural area, one that is capable of seeing the problems in this population's real life, also being capable of 
collectively managing the ways for social transformation.

Keywords: Ruralities; Psychology; Cultural-Historical Psychology

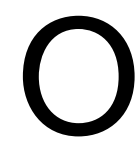

presente trabalho debruça-se sobre o estudo de algumas especificidades da vida em contextos rural e o trabalho do psicólogo. Através de levantamento bibliográfico pertinente, pudemos destacar que, no Brasil, quase exclusivamente a atuação do psicólogo no meio rural se dá por meio de estratégias de políticas públicas, representada pela atuação em Centros de Referência de Assistência Social (CRAS). Nesse levantamento, procurou-se enfatizar os saberes necessários ao psicólogo que deseja atuar ou já está atuando no meio rural, seja através do CRAS, Organizações Não Governamentais (ONG's), ou outras entidades cujos interesses se concentrem em trabalhos com essa população específica.

Primeiramente apontamos índices sobre a população rural e o modo como o Psicólogo brasileiro chega para atuar neste contexto. Em seguida nos dedicamos a explorar a importância de que as ações do psicólogo neste meio estejam amparadas em subsídios de uma Psicologia de fato comprometida com questões eminentes à vida rural, enfatizando para isso a visão de homem e de mundo da Psicologia históricocultural.

Objetiva-se com esse trabalho traçar reflexões pertinentes à prática do psicólogo em meio rural, destacando a necessidade de uma formação acadêmica bem embasada epistemologicamente; conhecer as maneiras como a Psicologia chega ao campo em nosso país; e por fim apontar o compromisso ético como necessário à uma psicologia que se pretende transformadora ao atuar na área rural. 


\section{A vida no contexto rural na América Latina e Brasil}

Durante a maior parte da história de nossa civilização, a população viveu predominantemente no meio rural. Somente a partir do ano de 2007 atingimos o índice que aponta que mais da metade da população mundial passou a viver em áreas urbanas.

Esta estatística também se aplica à América Latina, entretanto, cabe destacar que apesar da população desta parte do mundo viver predominantemente na área urbana, temos o expressivo número de 120 milhões de pessoas vivendo na área rural.

Falando especificamente sobre o Brasil, de acordo com o Instituto Brasileiro de Geografia e Estatística (IBGE) em 2015 a população brasileira era de 204.450.649 pessoas, sendo que $85,3 \%$ das pessoas viviam em cidades e $14,7 \%$ em áreas rurais (Instituto Brasileiro de Geografia e Estatística, 2016).

Segundo Baquero e Klein (2012), a escassez de terras produtivas, somada às más condições do emprego no campo e o melhor acesso aos serviços básicos que as cidades oferecem são alguns dos fatores que podem favorecer o crescente êxodo rural.

Uma especificidade com relação à vida em contexto rural que ora se faz importante destacar refere-se ao índice de pobreza. De acordo com Baquero e Klein (2012), há no mundo cerca de 1.2 bilhões de pessoas vivendo em situação de pobreza extrema o que é considerado quando uma pessoa sobrevive recebendo menos de 1,25 dólares por dia. Dentre estas pessoas que vivem em situação de pobreza extrema, mais de 75\% vivem em áreas rurais, ou seja, na área rural no mundo existem mais de 900 milhões de pessoas vivendo em condição de extrema pobreza. No caso específico do Brasil, na zona rural residem mais pessoas pobres (54,4\%), que não pobres $(43,4 \%)$. Como pode ser apreciado através dos dados quantitativos apresentados no anterior parágrafo, somado ao contínuo fenômeno do êxodo rural que permeia nossa sociedade contemporânea, uma questão preocupante se apresenta: a existência de 
um grande contingente da população rural brasileira que vive em condições de pobreza e vulnerabilidade. Para dar conta da complexidade da questão, é essencial o conhecimento e a compreensão das dinâmicas que atravessam o modo de existir dos homens e mulheres do campo, com vistas à formulação de ações efetivas de enfrentamento de nossas mazelas sociais. Ilustra-se assim a necessidade estratégica de estudos mais específicos que tratem dessa população, uma vez que a Psicologia enquanto ciência ainda não se debruçou de maneira satisfatória sobre as especificidades oriundas da realidade e das necessidades dessa população (Landini, 2015).

\section{Como a Psicologia chega ao campo: a atuação do CRAS}

Uma das primeiras indagações que instigou o presente trabalho foi a de saber como a Psicologia chega na zona rural, e quem são os psicólogos que atuam junto a esse público.

Dentro das Políticas Públicas, o equipamento que atua junto às populações rurais é o Centro de Referência de Assistência Social (CRAS). O CRAS é responsável pela proteção social básica, atuando nas regiões de risco e vulnerabilidade social, e é tido como a porta de entrada da população aos outros serviços disponibilizados pela rede de assistência social. Para alcançar seus objetivos, a equipe interdisciplinar do CRAS busca desenvolver as potencialidades pessoais e comunitárias, fortalecer vínculos familiares e comunitários, assim como ampliar o acesso da população aos seus direitos fundamentais como cidadãos (Ministério do Desenvolvimento Social e Combate à Fome, 2009).

$\mathrm{Na}$ cidade ou no campo, para que as necessidades reais e as situações de vulnerabilidade sejam detectadas, a equipe do CRAS realiza um mapeamento do local para análise da situação na qual a comunidade se encontra, identificando as influências que afetam a vida da comunidade analisada e propondo estratégias de 
enfrentamento aos problemas vigentes (Ministério do Desenvolvimento Social e Combate à Fome, 2009).

$\mathrm{Na}$ tentativa de visualizar quantitativamente o alcance que o CRAS pode ter na zona rural, observaremos alguns dados: em 2015 existiam 8.155 CRAS distribuídos por todo território brasileiro atendendo a 11.308 .128 famílias em situação de vulnerabilidade. Entre o total de CRAS existentes no território brasileiro, 325 estão localizados em território rural, o que representa $4 \%$ do total de CRAS do Brasil. É importante ressaltar que não apenas os CRAS localizados na zona rural atendem a essa população específica, já que vários CRAS se desdobram, dentro de suas possibilidades, no atendimento do campo e da cidade, possuindo equipes que se deslocam visando o atendimento à população em territórios extensos e áreas isoladas. Apenas $16,4 \%$ dos CRAS em nossa nação possuem equipe técnica adicional específica para tal tarefa, sendo essa equipe chamada de CRAS volante (Ministério do Desenvolvimento Social e Combate à Fome, 2016).

Segundo as orientações técnicas do CRAS, cada centro deve contar com uma equipe mínima de referência, que é relativa ao número de famílias por ele atendidas. Assim, por exemplo, quando determinado CRAS possui até 2500 famílias referenciadas, deve possuir em sua equipe mínima 2 técnicos com nível médio e 2 com nível superior, sendo um assistente social e outro preferencialmente psicólogo. Somente a partir de 5.000 famílias referenciadas a presença do profissional psicólogo deixa de ser preferencial e passa a ser obrigatória (Ministério do Desenvolvimento Social e Combate à Fome, 2009).

Com o propósito de monitorar a qualidade dos CRAS no Brasil, o Sistema Único da Assistência Social (SUAS) produz todos os anos dados sobre os Indicadores de Desenvolvimento do CRAS (IDCRAS), onde cada unidade referenciada do território nacional é pontuada segundo uma análise da estrutura física, dos recursos humanos e 
dos serviços e benefícios oferecidos. A escala varia de 1 a 5 , sendo 5 a pontuação máxima (Nunes \& Clemente, 2015).

Segundo o IDCRAS do ano de 2014, quase a metade das unidades (45\%) apresentava um nível de desenvolvimento aceitável, entre 3 e 4 . Porém ainda uma boa parcela das unidades, cerca de 34\%, atingiram um nível de 2 ou menos, o que demonstra que há grandes desafios a serem transpostos. Todos esses índices demonstram que existem vários CRAS atuando sem a equipe mínima completa, tanto em relação aos técnicos de nível médio, quanto aos técnicos de nível superior, onde se enquadram os psicólogos. Estes dados dão algumas indicações de que os recursos humanos na área da Psicologia ainda não condizem com a demanda real de intervenção (Nunes \& Clemente, 2015).

Diante dessa realidade, as diretrizes sugeridas na cartilha do Conselho Federal de Psicologia (CFP) para o psicólogo que atua no contexto de CRAS são claras: o profissional deve focar-se em compreender primeiramente os fenômenos sociais enfrentados subjetivamente por cada pessoa, e desta forma, pode sugerir ações que influenciem esses fenômenos, não se limitando apenas ao consultório, mas se envolvendo com a realidade da comunidade e entendendo realmente as necessidades e anseios desta. Isso significa um esforço por parte do psicólogo que atua em áreas rurais no sentido de realmente conhecer as especificidades dessa população (Conselho Federal de Psicologia, 2007).

Nessa mesma publicação direcionada aos psicólogos, o CFP sugere que a compreensão conjunta de homem, entendido como complexo e multideterminado, nos mostra o ser humano sendo influenciado pelas dimensões histórica, cultural e social, possibilitando um olhar mais cuidadoso a cada indivíduo, contemplando os diversos fatores que englobam a vida em sociedade. E a busca dessa análise complexa e multideterminada deve encontrar-se internalizada no psicólogo que atue no CRAS (Conselho Federal de Psicologia, 2007). 
O atendimento do psicólogo nesse contexto, conforme proposto nas regulamentações vigentes, é de cunho individual ou grupal, e sempre prioriza o trabalho coletivo, para que possa envolver o indivíduo, sua família e a comunidade no processo. Mas para que o programa obtenha seus melhores resultados, é necessária a união entre áreas, ou seja, o trabalho multidisciplinar e intersetorial, visando uma compreensão mais ampla da comunidade e seus moradores. Dessa forma, a psicologia se une à pedagogia, à assistência social, à sociologia e a diversas outras áreas que buscam compreender melhor o homem em sociedade (Conselho Federal de Psicologia, 2007). Imbuídos dessas indicações, os profissionais da Psicologia devem tomar à sério a tarefa de conhecer seu objeto de estudo, fugindo tanto de tecnicismos quanto de psicologismos. Nesse sentido, uma reflexão criteriosa sobre os atravessamentos que permeiam esse modo de existir faz-se necessária para guiar uma atuação pertinente do psicólogo no meio rural.

\section{Psicologia e ruralidades}

Investigando a produção de autores da Psicologia que tratam do tema ruralidades, percebe-se a atenção que é dada a temas como: compreensão das especificidades do meio rural; psicologia ambiental; influência do meio social na formação do psiquismo; importância dos vínculos comunitários e por fim a formação e o papel do psicólogo que atua nesse meio específico. A partir disso, pretende-se explorar cada um desses pontos com vistas a subsidiar as reflexões necessárias para o desenvolvimento desse trabalho.

Como instrumento teórico para analisar o tema das ruralidades, pretende-se utilizar a Psicologia Histórico-Cultural, que encara o homem como um ser que constrói a sociedade onde vive e ao mesmo tempo é construído por ela dentro de um processo dialético, tendo suas condições de vida constituídas pelas condições externas objetivas e subjetivas (Bomfim \& Furlani, 2013). 


\section{O olhar do psicólogo urbano sobre as ruralidades}

Analisando os anais dos congressos de Psicologia no Brasil dos últimos anos, Albuquerque (2002) afirma que embora pratiquemos uma ciência psicológica já aplicada ao brasileiro, ela ainda tem um matiz predominantemente urbano. No censo de 2000 , temos a informação de que $74,2 \%$ dos municípios brasileiros possuíam menos de 20000 habitantes, podendo ser considerados como de características rurais. Levanta-se pois a questão: por que nos dedicamos tão pouco à essa tão expressiva fatia da população?

$\mathrm{Na}$ tentativa de responder à essa questão, levanta-se a hipótese de que nos debruçamos com maior naturalidade sobre aqueles temas que conhecemos, sobre a realidade imediata que nos cerca. Sendo os psicólogos profissionais que realizaram seus estudos predominantemente em universidades localizadas no âmbito urbano, parece natural que sob o domínio do urbano conduzam sua vida de trabalho. Ao estarem locados nas cidades, os psicólogos se voltam aos problemas que aí ocorrem emergencialmente, ainda que o inchaço das metrópoles advenha grandemente do êxodo rural. Todo esse processo migratório que ocorre ainda hoje no país gera o desenraizamento familiar, marginalização e várias sequelas sociais, transformando as cidades em lócus de grandes empresas, de grandes bolsões de pobreza e delinquência. Nessa efusão de conflitos que ocorre no cotidiano das cidades brasileiras, os psicólogos são absorvidos quase que completamente pelas problemáticas que aí vicejam (Albuquerque, 2002).

Porém, apenas essa reflexão não explicaria por si só a concentração dos esforços da ciência psicológica na área urbana. Há que notar-se que a atividade agrícola vem diminuindo sua contribuição ao PIB (Produto Interno Bruto) a cada ano que passa. Já não somos puramente uma potência agrícola enquanto país, pois o Brasil vem adquirindo o status de nação onde predominam a produção industrial e a prestação de serviços. Dessa forma, a atividade rural veio perdendo sua importância 
gradativamente ao longo das últimas décadas, e seus reflexos no panorama econômico e social vieram diminuindo de intensidade. Ao incentivar a agricultura de larga escala em detrimento da agricultura familiar, um modelo por excelência patronal e concentrador de capital, chegamos a uma situação de "grande disparidade de renda e de qualidade de vida entre nossa população" (Albuquerque, 2002, p. 38). De todo esse contexto econômico, decorre a naturalizada atenção que quase todas as ciências dão aos maiores produtores de riqueza, que hoje se concentram nas cidades (Albuquerque, 2002).

Nesse sentido, percebe-se o quanto os fatores sócio históricos e econômicos determinam as problemáticas, os modos de vida e os desafios a serem enfrentados pela sociedade. Em busca de respostas, os psicólogos que compartilham uma visão comunitária da Psicologia em terras latino-americanas têm se debruçado sobre o imenso contingente de indivíduos que são moradores das zonas rurais de seus países. Tais profissionais entendem que as especificidades de um modo de vida tão diverso ao modo de vida urbano merecem uma ciência psicológica atenta e condizente à esse contexto, se almeja ser atuante e transformadora em sua ação. Há muito tempo faz-se necessário que a Psicologia realize uma troca das lentes urbanas para observar os fenômenos do contexto rural sem distorções e assim poder atuar de forma eficaz nesses ambientes (Landini, 2015).

Como bem pontuam Dimenstein e Leite (2013, p.19): "temos nos deparado com uma enorme lacuna de participação da Psicologia nessas discussões, especialmente no que diz respeito às ruralidades, aos modos de subjetivação, aos processos psicossociais e identitários no âmbito dos contextos rurais.". Quando utilizam o termo "ruralidades", os autores pretendem enfatizar que não existe apenas um modo de existir característico do meio rural, e sim muitas e várias expressões de subjetividade que coexistem nesse ambiente. 
Na maioria das vezes o imaginário do homem urbano vê o meio rural como um local idílico, de harmonia comunitária e belas paisagens naturais, como se fosse possível a inexistência de conflitos, tensões e sofrimentos nesse contexto. Observam-se também vários preconceitos ligados ao homem e à mulher do campo, tidos como atrasados, pobres e simplórios, e ao olhar para a ruralidade, pensa-se no rural como um só, não considerando a ampla gama de contextos, níveis sociais e situações vivenciadas por esses grupos (Landini, 2015).

Conforme apontaram Albuquerque e Pimentel (2004), existe uma tendência a se dicotomizar os ambientes urbano e rural, como se fosse impossível que ambos possuíssem uma área comum de intersecção de interesses. O senso comum não consegue visualizar ainda o rural permeado de outras atividades que não sejam agropecuárias, ou habitado por pessoas que não sigam o estereótipo do "jeca tatu", o caipira matuto e ignorante. Como toda generalização é perigosa, a análise dos significados e sentidos dos termos em uso em nossas sociedades também reveste-se de importância para qualquer ciência.

Baseando-se em uma análise sócio-histórica do meio rural, Albuquerque (2002) aponta que o Brasil já deixou de ter a atividade agrária como a principal fonte de desenvolvimento e renda para aquelas pessoas que residem no campo. Começa aí a mudança de olhar necessário para entender quem são o homem e a mulher do campo na atualidade, pois a sociedade rural abarca todos os membros que vivem em uma coletividade rural, quer se dediquem à agricultura ou não. Dentro dessa coletividade, encontra-se um grande contingente de pessoas que apenas residem no campo, porém se dedicam ao setor industrial e de serviços, transladando-se todos os dias para outras localidades para trabalhar. A fonte de renda no mundo rural já não é mais predominantemente oriunda da atividade agrária, e a população se vestiu de uma mescla de características que já não permitem uma classificação rápida e simplificadora sobre suas realidades e vivências. 
Nesse sentido, Monteiro (2015) aponta que já não podemos nos ater a uma visão maniqueísta que dicotomiza o rural-urbano como opostos, pois seria empobrecedor trabalhar com a ideia de que o rural é homogêneo. A pesquisadora cita que em seus mais de 20 anos de trabalho com o tema das ruralidades, construiu uma tipologia que diferencia três tipos de ruralidades. Primeiro, uma ruralidade extremamente empobrecida. Depois, existem espaços rurais enriquecidos, vinculados ao chamado agronegócio. O terceiro tipo de ruralidade seria um âmbito rural muito rico, segundo a autora, porém provido de uma riqueza que está além da renda econômica, posto que é constituído de riqueza cultural, ambiental e cognitiva, representada por comunidades rurais tradicionais, indígenas e quilombolas.

É nesse panorama cultural, com diferentes vivências do rural, diversos níveis de renda, de escolaridade, de saberes, que o psicólogo precisa se mover e ser capaz de apreender como as diversas percepções conversam e se afetam entre si, construindo um entorno humano rico e complexo. Sem esse olhar cuidadoso, é vã a tentativa de promover crescimento humano (Monteiro, 2015).

Diante dos diversos aspectos que influenciam a vida rural, e para a compreensão das bases que construíram nossa noção do que vem a ser o homem e a vida no campo, algumas reflexões históricas devem ser feitas.

\section{O legado histórico e a pobreza no campo}

A história da pobreza no campo tem sua gênese em nossa colonização. O Velho Mundo, sinônimo de urbanização e de civilizado, aporta no Novo Mundo, uma região batizada pelos europeus como primitiva, imatura, habitada por pessoas que foram prontamente catalogadas como incivilizadas. Encontram aqui um meio ambiente repleto de riquezas, e com naturalidade tratam a América Latina como o armazém de Europa, de onde podem retirar tudo, utilizando para tanto o trabalho escravo dos nativos, considerados uma espécie humana inferior. A conexão historicamente 
estabelecida entre aquele que é morador de uma zona considerada incivilizada e a oferta de mão de obra barata estava sendo assim formada, e reforçada pelos séculos seguintes de exploração de recursos e do capital social (Andrade, Conti, Rozas, Villafuerte, \& Zamora, 2015).

Para Conti (2015), esse caráter forçoso de exploração centro-periferia continua se dando nos dias atuais, quando o campesino se encontra acuado pela imposição de um sistema de produção que favorece o chamado agronegócio, em detrimento dos saberes e fazeres tradicionais da agricultura familiar. A dinâmica histórica não pode ser vista como simples elemento do passado, e sim como formadora de uma lógica que mantêm uma dicotomia urbano-rural como sinônimo de civilizado-incivilizado, e consequentemente de riqueza-pobreza.

Completando o quadro de desequilíbrio, nega-se à maior parte da população também acesso à informação, conhecimento e principalmente as tomadas de decisão políticas. É uma simplificação fácil querer justificar a pobreza que existe no campo em razão da escassez de informação e de formação ali existentes, e não perceber que tal fenômeno foi construído e legitimado através de um processo sócio-histórico (Dimenstein \& Leite, 2013).

Como outro fator que contribui na construção e manutenção da pobreza no meio rural, temos o processo de globalização que alterou o funcionamento e a composição das comunidades rurais tradicionais. Os campesinos tradicionais foram perdendo espaço para a modernização do meio rural, impulsionada fortemente pela exportação. Essas mudanças não afetaram apenas a estrutura econômica do campo, mas também a vida social. Atualmente, o campesino quase nunca obtém recursos suficientes para seu sustento e já não realiza troca de produtos com seus vizinhos da comunidade. Por vezes a vida na cidade aparece como uma alternativa para seus problemas financeiros, aumentando dessa forma os números do êxodo rural, em um processo 
que gesta cada vez mais grandes produtores e ameaça de extinção a agricultura tradicional familiar (Wanderley, 2000).

\section{O aporte da Psicologia Social Comunitária e as ruralidades: criando possibilidades}

Os primórdios da psicologia no Brasil mostram uma ciência focada em aspectos urbanos, geralmente importando conhecimentos de outros países, não buscando estudar as demandas reais da população brasileira. Esse olhar "urbanizado" acabou por excluir fatores fundamentais para uma psicologia integral, como por exemplo os fatores sócio históricos e os culturais (Martins, 2010).

Porém, a partir dos anos 60 o Brasil começa a construir um olhar mais próximo da população e de sua realidade. Nesta época buscam-se mudanças sociais e em todos os níveis da vida das pessoas, impulsionando a inserção dos psicólogos na saúde pública nacional e mais tardiamente a criação da Associação Brasileira de Psicologia Social (ABRAPSO), que configurou "um importante marco para a construção de uma psicologia crítica, política, histórica e comprometida com a realidade concreta da população brasileira" (Martins, 2010, p.86).

Andrade et al. (2015) pontuam que ao longo de sua história, a Psicologia não tem predominantemente se caracterizado por estar ao lado dos mais desfavorecidos, e sim por colocar-se ao trabalho da reprodução social, ou ainda por estar ao lado de uma administração acrítica dos chamados problemas sociais. Como exemplo desse citado acriticismo temos a ideia de empreendedorismo dentro do paradigma neoliberal, onde até mesmo a intervenção psicossocial pode estar impregnada dessa noção de desenvolvimento atrelada ao crescimento econômico, em detrimento de outros aspectos que passam a ser secundários.

Para exemplificar as artimanhas desse paradigma que tenta equiparar crescimento econômico a desenvolvimento humano, temos a reflexão de um extensionista rural do 
Chile, que após acompanhar os desdobramentos das políticas de desenvolvimento rural em seu país, afirma que "o único que conseguimos depois de muito tempo foi fazer que os velhinhos campesinos passassem a entender que agora já não eram campesinos, e sim empresários rurais" (tradução do espanhol pelos autores do presente artigo). Nessa afirmação pode ser notada a relação entre psicologia, ruralidade e políticas públicas, vislumbrando-se categorias psicossociais que podem ser postas a serviço da transformação das subjetividades, de maneira perversa como no exemplo, ou então geradora de empoderamento (Andrade et al., 2015, p.165).

Martín-Baró (1996), através de teoria que denominou Psicologia da Libertação, convida para uma reflexão que pretende nortear ações transformadoras da Psicologia, tendo como público alvo a grande maioria da população da América Latina, caracterizada pela situação de exploração, alienação e conformismo, que acaba por roubar das pessoas a capacidade de definir suas vidas.

O termo "libertação" é muito presente na Psicologia Comunitária, sendo definido como um processo construído com a comunidade, usando como base os processos históricos já observados, buscando o fortalecimento de escolhas e vivências autônomas nas pessoas, lançando as bases que podem levar a um processo de conscientização, em uma relação dialética de aprendizado dentro do grupo ou comunidade. Almeja-se aumentar a consciência dos indivíduos acerca da opressão e manipulação oriundas dos sistemas socioeconômicos e culturais. Sendo assim, "a justiça social, o compromisso com a vida e a solidariedade" tomam a frente dessa prática libertadora da Psicologia Social Comunitária (Cidade, Mendonça, Nepomuceno, Soares, \& Ximenes, 2008, p. 460).

Cidade et al. (2008) ainda trazem que na busca de autonomia e liberdade, ambos, indivíduo e comunidade podem pouco a pouco perceber os processos sutis de opressão, traçando um caminho possível de libertação. Um membro de uma comunidade só se sente realmente livre quando todos os outros membros desta 
também assim o são, havendo a possibilidade de que em outro momento esse movimento se expanda para outras comunidades. Isso significa construir uma sociedade onde todos são livres e desejam o mesmo aos outros.

Vivemos em uma sociedade extremamente injusta e desigual, onde todo o sistema está articulado de tal maneira que a maioria das pessoas não consegue encontrar uma saída, uma solução para seu problemas já cronificados. Porém, para Cidade et al. (2008, p.461) a prática da Psicologia Social Comunitária pode ser libertadora, pois realmente questiona e enfrenta o sistema vigente, é "tarefa realizadora por excelência, criadora, inventora, inovadora", destacando dentre várias práticas fundamentais o "desenvolvimento comunitário" onde as qualidades observadas pela comunidade e o psicólogo em conjunto são fortalecidas, e os pontos negativos são transformados conjuntamente.

De acordo com a proposta de Góis (2003), quando inserido em uma comunidade, o psicólogo deve levar em consideração e inteirar-se de todos aspectos psicossociais que formam a teia de relações dessa comunidade, sejam internos ou externos. Dessa forma, o psicólogo terá uma visão mais ampla das melhores ações a serem implementadas com o intuito de fortalecer a autonomia individual e comunitária, tanto quanto a liberdade.

Góis (2003, p.291), apoiado em Vygotsky (1983) e Lane (1984) ainda complementa trazendo que "o problema central então, não é a relação entre saúde e enfermidade, prevenção e tratamento, mas sim a construção do morador como sujeito da realidade". Considera-se então um "sujeito da comunidade" aquele indivíduo que entende a relação dialética de construção individual e comunitária, onde ele mesmo se percebe construtor de sua história e de sua comunidade, história essa, permeada por lutas, sofrimentos e alegrias (Góis, 2003).

Para Andrade et al. (2015), a Psicologia Comunitária na América Latina possui a pretensão e a missão de chegar a ser uma psicologia do desenvolvimento 
psicossocial, no sentido do desenvolvimento de indivíduos e de grupos, com vistas à autogestão. Dessa forma, pode ser coadjuvante no desenvolvimento de habilidades como a tomada de decisões, ações transformadoras, autodireção, identidade grupal, todos processos psicossociais. A Psicologia Social Comunitária pode colaborar para a compreensão da origem social do sofrimento psíquico e dos mecanismos que ajudam a manter uma qualidade de vida precária, e, ao mesmo tempo buscando fortalecer os indivíduos para que compreendam seus papéis de transformadores da realidade. Tal teoria oferece ainda um ferramental teórico e metodológico adequado para o trabalho do psicólogo que adentra no universo rural, com todos os seus desafios e dinamismos, merecendo por isso uma leitura cuidadosa, que poderá instrumentalizar o profissional da Psicologia para ser capaz de perceber a gênese da injustiça social, muitas vezes produtora do adoecer e das mazelas em nosso meio.

\section{A formação do psicólogo para atuação no meio rural: além da mera transposição} teórica

Uma das primeiras indagações que vem à mente ao ser levantado o tema da Psicologia em meio rural poderia ser: porque se necessitaria falar ou pensar acerca desse recorte tão específico? Interessante notar que tal discussão é um ponto chave para uma Psicologia que historicamente nem sequer tem considerado a ruralidade, os povos originários ou o campesinato como relevantes para a discussão. Não seria inusitado escutar-se o argumento de a Psicologia é Psicologia em todas as partes, e portanto não seria necessário de que nos ocupássemos na tarefa de desenvolvê-la em um contexto tão específico como o rural. Porém essa forma de pensar possui limitações, que surgem da pretensão de generalização de certas correntes teóricas dentro da Psicologia (Landini, 2015).

Nessa linha de pensamento, ainda que se aceite que os conhecimentos gerados pela prática científica psicológica possam ter pretensão universal, um uso apropriado 
desses saberes pressupõe uma contextualização adequada e atrelada às condições concretas da existência. De modo complementar, pode-se afirmar que a pretensão de generalização da Psicologia em contextos que estão muito além dos marcos históricos e sociais nos quais ela foi produzida poderia ser no mínimo ingênua. E se seguimos essa mesma linha de argumentação, segundo a Psicologia Histórico-Cultural, e aceitamos que as subjetividades são o resultado da interiorização das relações sociais, depreende-se que o contexto rural tem a potencialidade de produzir subjetividades imbuídas de uma especificidade que merecem uma consideração adequada. E a amarga pena da generalização rasa nos campos da ciência é a produção de um labor pouco efetivo, e muitas vezes mantenedor dos processos geradores de adoecimentos e outras problemáticas (Landini, 2015).

A Psicologia nasceu afiançando-se no método experimental associado às ciências naturais, formando uma corrente hegemônica que ainda mantém sua pujança nos dias atuais, com uma epistemologia positivista que a alicerça. Não desmerecendo sua imensa contribuição, Landini (2015) aponta que tal linha hegemônica não se deteve a analisar a construção cultural das subjetividades, em uma multiplicidade de cenários que devem ser um elemento central na análise e no fazer psicológico.

O mesmo autor propõe pensar a Psicologia em meio rural não como uma subdisciplina dentro da ciência psicológica, e sim como um "campo de problemas", onde se articulam psicologia e ruralidades, formando um conjunto de temas onde se torna muito relevante a consideração do contexto rural, da dimensão psicossocial e da dimensão psicológica, já que ao desprezar-se qualquer desses fatores a possibilidade de compreensão ou de intervenção seria prejudicada em aspectos cruciais.

O discurso científico nascido na academia é fruto de sua época, e não decorreu muito tempo desde que a Psicologia passou a estudar o meio rural e suas particularidades, e ainda existem poucos profissionais atuando nessa área. A psicologia necessita de avanços na formação que oferece à nível acadêmico, não existindo na maioria das 
universidades matérias específicas direcionadas ao universo rural e à atuação do psicólogo nesse meio. Muitas vezes a própria população rural ainda confunde o trabalho do psicólogo com o do médico ou do assistente social (Vasquez, 2009).

Diante desta falta de informação e de formação, e pensando em orientar os psicólogos para uma mais efetiva atuação em questões rurais, o CFP lança em 2013 o manual de "Referências Técnicas para Atuação das(os) Psicólogas(os) em Questões Relativas a Terra”, onde elenca uma série de saberes norteadores para um atuar ético e transformador junto às diferentes populações rurais: indígenas, agricultores familiares, quilombolas e assentados. Nessa publicação, o Conselho Federal de Psicologia (2013) destaca que onde quer que existam seres humanos explorados e desqualificados, e onde existam também novas possibilidades de existir querendo vicejar, existe uma demanda para o psicólogo. Onde exista uma tentativa de superação das condições que impõem sofrimento, que cerceiam a capacidade crítica e criativa, aí está um chamamento que deve ser escutado e interpretado pela Psicologia. A necessidade de compreender o conjunto de relações sociais que se estabelece no meio rural é o ponto de partida para o psicólogo: famílias com diferentes histórias de vida, funcionários dos organismos públicos, ONG's, representantes de distintas religiões, militantes de movimentos sociais. Em meio à essa complexidade e diversidade de perspectivas a Psicologia pode ser instrumento de transformação, nas mais diversas esferas da vida rural. O Conselho Federal de Psicologia (2013) aponta possíveis contribuições da Psicologia na assistência às populações rurais, envolvendo as esferas que vão desde o mundo rural, as atividades produtivas, as experiências organizativas, a saúde e a educação formal.

Para ser capaz de fazer frente a tão complexos desafios em sua atuação, a Psicologia deveria contar com uma formação que preparasse o profissional para uma relação vincular dialógica. Uma formação que o tornasse capaz de perceber que sua entrada em uma comunidade leva com ele toda uma carga cultural, e que esse contato deve 
leva-lo a uma indagação acerca da identidade do outro. Na medida que o profissional deixa transformar-se pela realidade do "outro", pode ir logrando transformações em uma dança dinâmica de afetações mútuas. Se a comunidade sentir e desejar assim, se apropriará das ferramentas ofertadas pelo profissional e as adequará para realizar as mudanças que julgar pertinentes. Assim, nessa relação dialógica a transformação é possível, em um processo de co-criação coletiva (Becerra, Ceriani, Gonçalves, \& Petit, 2015).

\section{Discussão}

Os desdobramentos advindos das reflexões suscitadas no presente artigo entrelaçam necessariamente o compromisso ético e a utilização de uma epistemologia adequada para atuar em ambiente rural. Acreditamos que a contribuição de Martín-Baró à uma Psicologia que pretende ser libertadora deve ser relembrada para tanto: o trabalho de promover a conscientização das pessoas é o verdadeiro trabalho do psicólogo. E para uma pretensa "Psicologia Rural", seria menos importante preocupar-se com a segurança científica e o prestígio acadêmico, nos moldes de uma afirmação positivista, e mais com os problemas reais da população rural. Essa tarefa passa pela superação da noção romantizada do "bom homem do campo", passivo, acrítico e ingênuo, pois trata-se de auxiliar na construção de uma voz que se faça ouvir por parte dos povos campesinos, indígenas e afins (Becerra et al.,2015).

A análise do imaginário popular quando se fala em ambiente rural é determinante para a reflexão da ciência psicológica. Ainda permeado por uma dicotomia entre o urbano e o rural, como sendo necessariamente opostos, o senso comum pode construir preconceitos que se traduzem muitas vezes em descaso das instâncias públicas com os diversos universos que permeiam a vida no campo. Uma consequência dessa arraigada dicotomia é o investimento público dirigido somente à produção agrária quando se trata da área rural, como se ali não existissem todas as necessidades 
humanas como educação, lazer, saúde, necessidade de geração de emprego e renda (Albuquerque \& Pimentel, 2004).

Como bem pontuam Albuquerque e Pimentel (2004), o investimento somente no setor primário de produção agrícola favorece principalmente os grandes proprietários de terra, beneficiários dessas subvenções, em detrimento da grande maioria da população rural, formada por agricultores familiares e empregados das grandes propriedades.

Vimos que uma das formas como a Psicologia chega ao campo, no Brasil, é através do CRAS, e nesse sentido, cabe uma reflexão pertinente em relação ao que significa trabalhar em políticas públicas que foi tecida por Andrade et al. (2015), quando afirma que muitas vezes as mesmas podem não ser nem "políticas" e nem "públicas", pois se nos remetemos à palavra "política" como significando transformação do que está dado e "pública" como orientação ao bem estar de pessoas e grupos, temos um longo processo de transformação pela frente, e enquanto psicólogos, devemos estar instrumentalizados para colaborar nessa tarefa coletiva.

O breve vislumbre dos números do SUAS que foi apresentado neste artigo nos mostra que apesar dos avanços dessa política pública, ainda possuímos grandes desafios a serem enfrentados. A carência de recursos humanos e objetivos culmina em uma quase impossibilidade de que sejam comtempladas as necessidades dos brasileiros do campo, uma vez que, conforme apontamos anteriormente, cerca de $14 \%$ da população brasileira vive em contextos rurais. (Ministério do Desenvolvimento Social e Combate à Fome, 2016; Instituto Brasileiro de Geografia e Estatística, 2016).

Como bem pontuam Becerra et al.(2015), em algumas intervenções o psicólogo que atua em organismos públicos pode estar sendo um mero repetidor acrítico de técnicas dentro de marcos estatais, e muitas vezes desconhecendo o impacto real que essa trama institucional tem sobre as populações. Quando um psicólogo ingressa em uma comunidade como agente de alguma política pública, de que lado se posiciona, à 
quem ele serve? Talvez possa ser construída uma nova relação usuários-política pública a partir de um atuar crítico, ético e bem embasado epistemologicamente.

Concluímos o presente trabalho destacando que a compreensão de que o rural é mais que uma grande extensão de monocultura pode impactar diretamente a vida de muitas pessoas, e a Psicologia pode contribuir com propriedade para essa mudança de paradigmas, ajudando a construir a possibilidade de permanência das pessoas que desejem viver a vida e o trabalho no campo. Como efeito positivo, o grande êxodo rural que ainda incha os bolsões de pobreza das metrópoles poderia ser diminuído, e o cidadão que deseja voltar ao campo poderia vislumbrar alguma possibilidade real de melhoria de qualidade de vida.

Apoiados nos dados e estudos aqui apresentados, propomos que o Psicólogo que pretende atuar em contextos rurais, deve buscar, antes de mais nada, conhecer as especificidades da vida no campo, contemplando os aspectos econômicos, geográficos, sociais e políticos que ali se dimensionam e que impactam diretamente sobre a constituição da subjetividade de cada pessoa e que também impactam sobre toda a realidade de um país.

È preciso ainda que as metodologias de intervenção contemplem tais especificidades. No Brasil, o CRAS e as Unidades Básicas de Saúde representam uma porta de entrada para a atuação da psicologia no meio rural. Por meio do CRAS, intervenções em grupo com adolescentes, idosos e famílias em situação de vulnerabilidade podem acontecer em formato de oficinas, rodas de conversa e visitas domiciliares, por exemplo. Por meio das Unidades de Saúde pode-se propor atendimentos em saúde mental com intervenções individuais ou grupais, orientações a gestantes e atendimentos domiciliares, por exemplo.

Landini (2015) por sua vez, aponta várias possibilidades de ação para a Psicologia no campo, como por exemplo trabalhar junto aos extensionistas rurais, facilitando a comunicação e o entendimento dos processos vivividos pela população do local, 
tornando assim a assistência técnica mais resolutiva. Destaca ainda o nicho aberto para a Psicologia na área da saúde, onde o processo de saúde-doença-prevenção dessa população específica precisa ser contextualizado junto aos profissionais de saúde e junto aos usuários, na construção de uma atenção mais efetiva. Dentro da área da educação no campo e também junto aos povos originários, as possibilidades de intervenção são múltiplas, como fortalecimento da identidade e valorização da cultura local.

Moura Junior, Cardoso, Rodrigues, Vasconcelos e Ximenes (2013) publicaram o trabalho Práxis em psicologia comunitária: festa de são joão como atividade comunitária, onde relatam uma intervenção em Psicologia a partir da inserção do psicólogo na organização de uma atividade festiva. Os autores apontam tal atividade como caminho de intervenção junto à comunidade tanto pela valorização de cada etapa de participação da comunidade na preparação do festejo como modo de aproximação e fortalecimento de saúde mental, como também pela identidade de comunidade que pode ser fortalecida por meio da valorização da expressão popular. Este trabalho pode ser citado como um exemplo de intervenção que metodologicamente contempla o conhecimento de realidade e que permite uma prática psicológica contextualizada.

Precisamos nos ater à necessidade de que esta temática seja mais amplamente investigada e passe a compor conteúdo de formação básica de Psicólogos, frente a expressiva porcentagem de pessoas que vivem em contextos rurais e também frente à importância que as questões agrárias representam ao desenvolvimento do nosso país.

\section{Referências}

Albuquerque, F. J. B. (2002). Psicologia Social e Formas de Vida Rural no Brasil. Psicologia: Teoria e Pesquisa, 18(1), 37-42. 
Albuquerque, F. J. B., \& Pimentel, C. E. (2004). Uma Aproximação Semântica aos Conceitos de Urbano, Rural e Cooperativa. Psicologia: Teoria e Pesquisa, 20(2), 175-182.

Andrade, R.R., Conti, S., Rozas, G., Villafuerte, \& Zamora, C., (2015). Relaciones entre psicologia comunitária y ruralidad. En F. Landini (Coord.), Hacia una psicología rural latino-americana (pp.163-167). Buenos Aires: CLACSO.

Baquero F. S., \& Klein E. (2012). Políticas de Mercado de Trabajo y pobreza rural en América Latina. Roma: Food and Agricultural Organization of the United $\begin{array}{llll}\text { Nations } & \text { (FAO). } & \text { Recuperado }\end{array}$ http://www.redetis.iipe.unesco.org/publicaciones/politicas-de-mercado-detrabajo-y-pobreza-rural-en-america-latina-tomo-i/\#.WpX8IGrwbIU

Becerra, J. B., Ceriani, V., Gonçalves, B. S., \& Petit, L. (2015). Psicología rural y pueblos originários. En Landini, F. (Coord.), Hacia una psicología rural latinoamericana (pp. 293-306). Buenos Aires: CLACSO.

Bomfim, D.D \& Furlani, Z.A.C. (2013). Jovens de ambiente rural e urbano e sua relação com projetos de vida. En J.F. Leite y M. Dimenstein (Coords.), Psicologia e Contextos Rurais (pp.117-142). Natal-RN: EDUFRN.

Cidade, E. C., Mendonça, F. W. O., Nepomuceno, L. B., Soares, C., \& Ximenes, V. M. (2008). Por uma psicologia comunitária como práxis de libertação. Psico, 39, 456-464.

Conselho Federal de Psicologia (2013). Referências Técnicas para Atuação das(os) Psicólogas(os) em Questões Relativas a Terra. Brasília: CFP.

Conselho Federal de Psicologia (2007). Parâmetro para atuação de assistentes sociais e psicólogos(as) na Política de Assistência Social. Brasília: CFP/CEFESS.

Conti, S. (2015). El trabajo associativo em la economia social. Tensiones alrededor del desarrollo rural em la provincia de Río Negro, Argentina. En F. Landini, F. 
(Coord), Hacia una psicología rural latino-americana (pp.169-173). Buenos Aires: CLACSO.

Dimenstein, M., \& Leite, J.F. (Coods.) (2013). Psicologia e contextos rurais. Natal-RN: EDUFRN.

Góis, C. W. L. (2003). Psicologia Comunitária. Universitas Ciências da Saúde, 1(2). Recuperado de http://www.publicacoesacademicas.uniceub.br/index.php/cienciasaude/article/vi ewFile/511/332

Instituto Brasileiro de Geografia e Estatística (2016). Países: Brasil. Recuperado de http://paises.ibge.gov.br/\#/pt/pais/brasil/info/populacao

Landini, F. (Coord.) (2015). Hacia una psicología rural latino-americana. Buenos Aires: CLACSO.

Lane, S. T.M. (1984). A Psicologia Social e uma nova concepção do homem para a Psicologia. En W. Codo y S. T. M. Lane (Coords.), Psicologia Social: o homem em movimento (pp.10-19). São Paulo: Editora Brasiliense.

Martín-Baró, I. (1996). O papel do psicólogo. Estudos de Psicologia, 2(1), 7-27.

Martins, A.M. (2010). A formação em Psicologia e a percepção do meio rural: um debate necessário. Psicologia: Ensino \& Formação, 1(1), 83-98.

Ministério do Desenvolvimento Social e Combate à Fome (2009). Orientações Técnicas: Centro de Referência de Assistência Social - CRAS (1th ed.). Brasília: Ministério do Desenvolvimento Social e Combate à Fome.

Ministério do Desenvolvimento Social e Combate à Fome (2016). Censo SUAS 2015. Resultados Nacionais- Centros de Referência da Assistência Social, CRAS. Brasília: Ministério do Desenvolvimento Social e Combate à Fome.

Monteiro, R.C. (2015). Educación y ruralidades contemporáneas. Aportes psicológicos para el debate. En F. Landini, F. (Coord), Hacia una psicología rural latinoamericana (pp. 103-106). Buenos Aires: CLACSO. 
Moura Junior, J.F, Cardoso, A. A. V, Rodrigues, D. C, Vasconcelos, R. M., \& Ximenes, V. M. (2013). Práxis em psicologia comunitária: festa de São João como atividade comunitária. Revista Ciência em Extensão, 9(1), 105-123.

Nunes, H. M. P., \& Clemente, P. E. (2015). Nota Técnica n²7/2015/DGSUAS/SNAS/MDS. Metodologia de cálculo relativa aos novos indicadores de desenvolvimento das unidades CRAS e CREAS - IDCRAS e IDCREAS referentes ao ano de 2014. Brasília: Ministério do Desenvolvimento Social e Combate à Fome. Recuperado de http://www.social.mg.gov.br/images/documentos/capacita_suas/Material_consul ta/Nota_tecnica_IDCRAS_IDCREAS_2014.pdf

Vasquez, G. C. F. (2009) A Psicologia na área rural: os assentamentos da reforma agrária e as mulheres assentadas. Psicologia Ciência e Profissão, 29(4), 856867.

Vygotsky, L. S. (1983). Obras Escogidas: Problemas del desarrollo de la psique. (Lydia Kuper, Trad.). Madrid: Visor.

Wanderley, M. N. B. (2000). A emergência de uma nova ruralidade nas sociedades modernas avançadas - o "rural" como espaço singular e ator coletivo. Estudos Sociedade e Agricultura, 15, 87-145.

\section{Formato de citación}

Lopes, E., Catelan, C., Renan, D. (2018). Psicologia e ruralidades: caminhos para um fazer psicológico transformador. Psicología, Conocimiento y Sociedad, 8(1), 262-287. doi: http://dx.doi.org/10.26864/PCS.v8.n1.12 